\title{
Production of Oyster Mushrooms in Different Seasonal Conditions of Bangladesh
}

\author{
M. N. Uddin ${ }^{1}$, S. Yesmin ${ }^{1}$, M. A. Khan ${ }^{1,2, *}$, M. Tania ${ }^{1,2}$, M. Moonmoon ${ }^{1}$, and S. Ahmed ${ }^{1}$ \\ ${ }^{1}$ National Mushroom Development and Extension Centre, Savar, Dhaka 1340, Bangladesh \\ ${ }^{2}$ Department of Biochemistry, School of Biological Science and Technology, Central South \\ University, Changsha, Hunan 410013, China
}

Received 21 September 2010, accepted in revised form 22 October 2010

\begin{abstract}
Oyster mushrooms (Pleurotus spp.) are widely cultivated all over the world. Its production is remarkably affected by the environmental conditions like temperature and relative humidity. In this study, we investigated the production of four species of oyster mushroom: Pleurotus ostreatus, $P$. florida, $P$. sajor-caju and $P$. high king cultivated in every season (January to December) in Bangladesh. The temperature (in ${ }^{0} \mathrm{C}$ ) and relative humidity $(\% \mathrm{RH})$ of culture house in each month, and parameters of mushroom production were recorded. In all of the selected species of this study, the minimum days required for primordial initiation, and the maximum number of fruiting bodies, biological yield and biological efficiency were found during December to February $\left(14-27{ }^{0} \mathrm{C}, 70-80 \% \mathrm{RH}\right)$. The production was found minimum during the cultivated time August to October. We suggest cultivation of selected Pleurotus spp. in winter (temperature zone $14-27{ }^{0} \mathrm{C}$ with relative humidity $70-80 \%$ ) for better production and biological efficiency.
\end{abstract}

Keywords: Pleurotus mushroom; Different seasonal conditions; Growth and yield; Biological efficiency.

(C) 2011 JSR Publications. ISSN: 2070-0237 (Print); 2070-0245 (Online). All rights reserved.

doi:10.3329/jsr.v3i1.6130 J. Sci. Res. 3 (1), 161-167 (2011)

\section{Introduction}

Mushrooms are being recognized as important food items from ancient times. Their usage is being increased day by day for their significant role in human health, nutrition and disease. Mushrooms of Pleurotus spp. are commonly known as oyster mushrooms which occupy the second position among cultivated edible mushrooms worldwide due to their nutritional and medicinal values [1]. The environmental factor is very important for the production of oyster mushrooms. Various mushrooms are known to be sensitive to the climatic conditions [2]. The major environmental factors like temperature, humidity, fresh air and compact materials affect in mushroom production [3-5].

\footnotetext{
*Corresponding author: asadkhanbmj@yahoo.com
} 
Pleurotus spp. grows in wide range of temperature $\left(15-30{ }^{0} \mathrm{C}\right)$ which also varies from species to species [6]. Bano and Rajarathnam [7] observed maximum yield of oyster mushroom (Pleurotus sajor-caju) during rainy seasons, when the temperature was nearly $20-26{ }^{0} \mathrm{C}$ and relative humidity $70-90 \%$. A fairly good yield can be obtained up to $30{ }^{\circ} \mathrm{C}$. Production of $P$. fossulatus prefers $20 \pm 1{ }^{0} \mathrm{C}$ but $P$. eous prefers $21-35{ }^{\circ} \mathrm{C}$ and humidity of 65 to $100 \%$ [8]. Maximum growth of $P$. ostreatus was recorded at $25{ }^{0} \mathrm{C}$ by Rangad and Jandaik [9], whereas $P$. florida gave the highest yield at $30{ }^{\circ} \mathrm{C}$. P. flabellatus also have a similar temperature requirement $[10,11]$. Kong [12] reported that $P$. ostreatus, $P$. florida, $P$. sajor-caju reach their optimum growth at $25{ }^{\circ} \mathrm{C}$, while $P$. cornucopiae and $P$. cystidiosus reach their optimum growth at $25-35{ }^{0} \mathrm{C}$ temperature.

In Bangladesh, oyster mushrooms are most popular and four different species of this mushroom like Pleurotus ostreatus, P. florida, P. sajor-caju and P. high king are commercially cultivated all over the year by using sawdust and/or rice straw as main substrate [13]. But the productions of these mushrooms are not economically beneficial in every season. The environmental variation is supposed to be the main cause behind this problem. But the performances of these species of oyster mushroom have not yet properly been investigated in the climatic conditions of different seasons. Therefore the present study was undertaken to identify the specific season or cultivation time for the four specific species of oyster mushroom.

\section{Materials and Methods}

The experiment was conducted at the National Mushroom Development and Extension Centre, Sobhanbag, Savar, Dhaka during January to December, 2009. Four selected species of oyster mushroom such as, Pleurotus ostreatus, $P$. florida, P. sajor-caju and $P$. high king were cultivated in the culture house of the centre.

\subsection{Spawn packet preparation and inoculation of mother culture}

The substrate of oyster mushroom was prepared by using sawdust and wheat bran at the ratio of $2: 1$. Calcium carbonate was added at $0.2 \%$ of the substrate mixture and the moisture was adjusted at $65 \%$ by adding water. The mixture was filled into heat tolerant polythene bags (500 g/ packet) of 7" $\times 10$ " size and their mouth were plugged by inserting water absorbing cotton and covered with brown paper and tied with a placing rubber band. Then bags were autoclaved at $121{ }^{\circ} \mathrm{C}$ and 15 PSI for 1 hour and then allowed to cool. Spawn packets were inoculated separately with the mother culture of selected species of oyster mushroom at the rate of two teaspoonfuls per packet. Packets were then incubated for mycelium running and mushroom cultivation in the incubation room at $25{ }^{\circ} \mathrm{C}$.

\subsection{Experimental conditions}

After 30 days of inoculation, when mycelium running was completed, the spawn packets were transferred to culture house and opened by D-shaped $(1 " \times 2 ")$ cut on the shoulder of the spawn packets. Temperature and relative humidity of culture house and the outside places throughout the year is given in Table 1. 
Table 1. Temperature and relative humidity of culture house and outside during oyster mushroom cultivation throughout the year.

\begin{tabular}{|c|c|c|c|c|c|c|c|c|c|c|c|c|}
\hline & Jan & Feb & Mar & April & May & June & July & Aug & Sep & Oct & Nov & Dec \\
\hline $\begin{array}{l}\text { Temp. }\left({ }^{0} \mathrm{C}\right) \text { of } \\
\text { culture house }\end{array}$ & $14-25$ & $14-25$ & $22-30$ & $22-33$ & 23-33 & $24-30$ & $23-30$ & $25-30$ & $25-30$ & $24-30$ & $20-28$ & $16-27$ \\
\hline $\begin{array}{l}\text { RH (\%) of } \\
\text { culture house }\end{array}$ & $72-80$ & $70-80$ & $70-78$ & 71-78 & $72-79$ & $80-88$ & $75-88$ & $90-95$ & $85-90$ & $80-90$ & $65-70$ & $70-80$ \\
\hline $\begin{array}{l}\text { Outside temp. } \\
\left({ }^{0} \mathrm{C}\right)\end{array}$ & $16-28$ & $20-32$ & $23-34$ & $24-33$ & $26-32$ & 26-32 & 26-31 & 26-31 & $26-31$ & $24-31$ & $20-29$ & $14-26$ \\
\hline $\begin{array}{l}\text { Outside } \\
\text { RH (\%) }\end{array}$ & $50-58$ & $47-51$ & $42-48$ & $50-60$ & $68-76$ & $77-81$ & $75-85$ & $76-80$ & $75-81$ & $70-74$ & $65-67$ & $60-66$ \\
\hline
\end{tabular}

RH: Relative humidity.

\subsection{Harvesting}

Mushroom was harvested before the fruiting body showed any splitting on the edges. The yield of mushrooms and their different quality parameters: days required to first primordial initiation (DPI), number of effective fruiting bodies (NFB) and biological yield were recorded regularly. Biological efficiency (BE) was determined by the following formula:

$$
\mathrm{BE}=(\text { wt. of fresh mushroom fruiting bodies }) \times 100 / \text { wt. of dry substrate }
$$

\section{Results}

The DPI in four species ranged from 5 to 8 days (Fig. 1). The lowest time (5 days) was required for DPI of $P$. ostreatus and $P$. high king in January which was followed by $P$. sajor-caju (5.5 days) in December. The maximum DPI (8 days) was recorded for $P$. ostreatus in April, May and August; for P. florida in March to May, August and November; for P. sajor-caju in March, July and August; for P. high king in March, September and October.

\section{$\square$ P. ostreatus $\square$ P. florida $\square$ P. sajor-caju $\square$ P. high king}

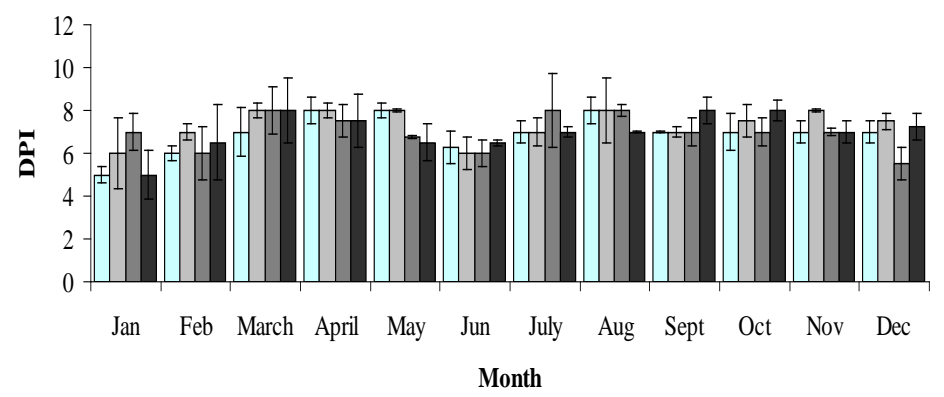

Fig. 1. Days required to first primordial initiation (DPI) of selected Pleurotus spp. in different month of the year. Values are mean \pm SEM of 10 replicate. 
Fig. 2 shows that NFB of selected species in different months of the year, ranging from 6.0 to 44.0. The highest NFB (44.0) was produced in P. ostreatus in December followed by $P$. florida in January and the lowest NFB was produced in $P$. ostreatus in September (6.0) and $P$. high king in August (6.0) which was almost similar to P. sajorcaju in October (6.25). In all of the selected species of this study, the maximum NFB was found in December to March, moderate NFB in April to July and minimum NFB was found in August to November.

$\square$ P. ostreatus $\square$ P. florida $\square$ P. sajor-caju $\square$ P. high king

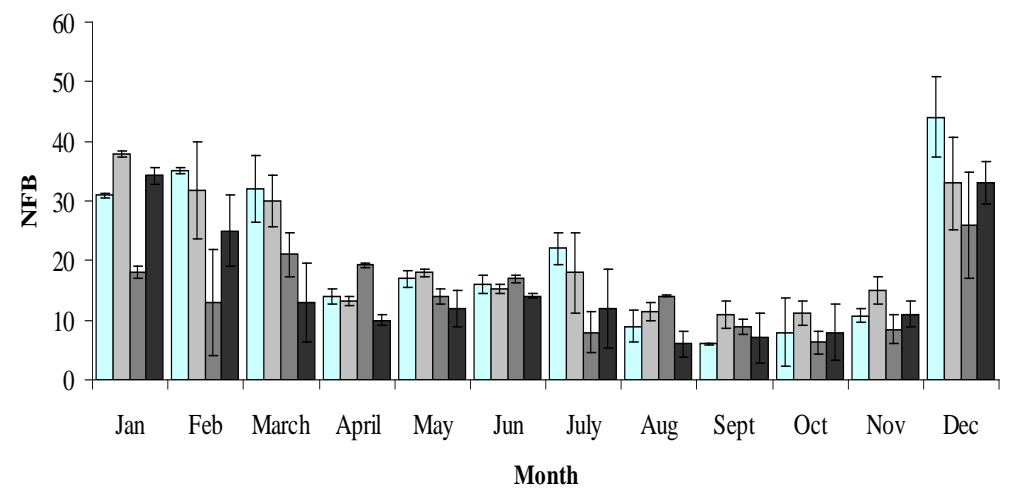

Fig. 2. Number of effective fruiting bodies (NFB) of selected Pleurotus spp. in different month of the year. Values are mean \pm SEM of 10 replicate.

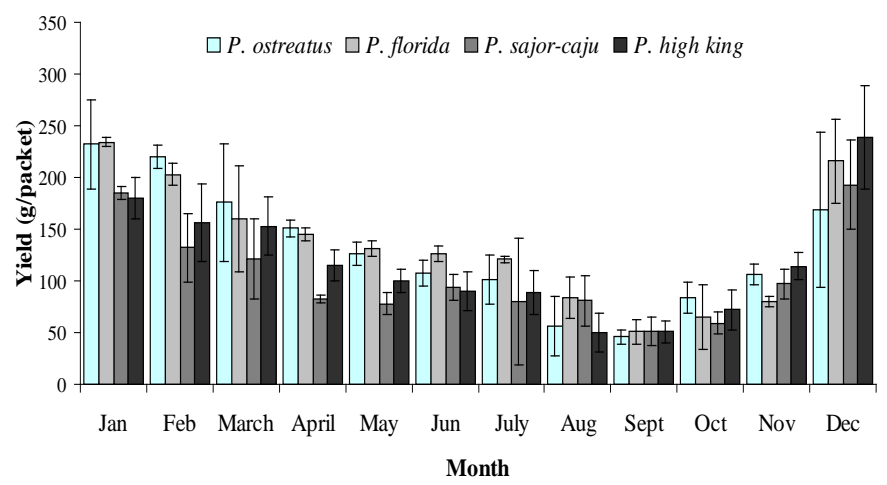

Fig. 3. Biological yield of selected Pleurotus spp. in different month of the year. Values are mean \pm SEM of 10 replicate.

The biological yield of four selected species of oyster mushroom throughout the year is shown in Fig. 3. The yield ranged from 46.0 to 239.0 g/packet, with the maximum yield in $P$. high king in December and minimum yield in P. ostreatus in September. In case of $P$. ostreatus, maximum yield (232.0 g/packet) was found in January and minimum yield (46.0 g/packet) in September. Similar result was observed in P. florida with maximum 
yield in January (234.0 g/packet) and minimum yield in (51.0 g/packet) in September. In P. sajor-caju, the maximum yield (193.0 g/packet) was observed in December and minimum yield (51.0 g/ packet) in September. In P. high king, the maximum yield (239.0 g/packet) was observed in December and minimum yield (50.0 g/packet) in August.

Fig. 4 shows the pattern of change of BE throughout the year. The BE of selected species in different month of the year ranged from 23.0 to $119.5 \%$. The highest BE (119.5 \%) was recorded to $P$. high king in December and the lowest (23.0\%) to P. ostreatus in September which was followed by P. high king in August. In case of all species, BE maintained the similar trends of biological yield. From figure 3 and 4, it is clear that the $\mathrm{BE}$ and production of oyster mushroom reach in peaks which are cultivated in December, January and February. From March to July, the production and BE were found to be decrease and moderate. From August to October, the production and BE were in minimum level. From November, the production again increased.

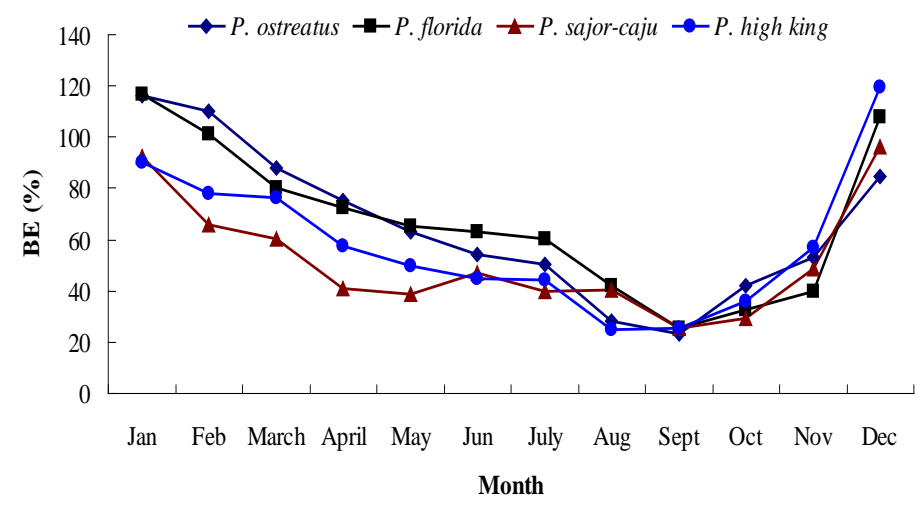

Fig. 4. Change of biological efficiency (BE) of selected Pleurotus spp. through different month of the year.

\section{Discussions}

In this study, we have found that the lowest time for DPI was recorded in January for all of the selected varieties when the average temperature and relative humidity of culture house were respectively, $14-25{ }^{0} \mathrm{C}$ and $72-80 \%$. Kong [12] reported that $10-25{ }^{0} \mathrm{C}$ temperature required for primordial formation of selected Pleurotus species. Our result is also similar to Viziteu [14], who reported that the required temperature is $18-25{ }^{0} \mathrm{C}$ for primordial formation of oyster mushroom.

According to Das et al. [15, 16], variations in season seriously affected the number, weight and crop production period of mushroom. They reported that favorable temperature and moisture condition enhanced the production of fruiting bodies of mushroom. The highest number of effective fruiting body was produced in December to February for selected Pleurotus species. During this time the average temperature and 
relative humidity of culture house were respectively, $14-27{ }^{0} \mathrm{C}$ and $70-80 \%$. Kong [12] also recommended $10-25{ }^{0} \mathrm{C}$ temperature for fruit body development of selected mushroom species. Tripathi [17] reported that $16-22{ }^{0} \mathrm{C}$ for P. ostreatus and $10-26{ }^{0} \mathrm{C}$ for $P$. florida and $P$. sajor caju were suitable for fruit body development.

Maximum yields of the selected four species were recorded from December to February when the average temperature and relative humidity of culture house were 14-25 ${ }^{0} \mathrm{C}$ and $72-80 \%$, respectively. Kong [12] reported that $P$. florida and P. sajor-caju produce best yield at $15-25{ }^{0} \mathrm{C}$ temperature. Upadhyay et al. [18] found maximum yield of $P$. membranaceus in October to January. The mild winter temperature was probably more conductive for the growth of Pleurotus mushrooms [19]. In this study, minimum yields of the selected four species were recorded in August to October when the average temperature and relative humidity of culture house were $24-30{ }^{0} \mathrm{C}$ and $80-95 \%$ respectively. During this period fungal infection and insect infestation were more, that is why it is supposed that production rate were reduced. Upadhyay et al. [18] also reported the minimum yield of P. membranaceus in June to September. Tripathi [17] suggested that $P$. ostreatus and $P$. florida give very poor yields during summer season. In our study, we have found the maximum biological efficiency of $P$. ostreatus and $P$. florida in January and of $P$. sajor-caju and P. high king, in December. According to Annual Progress Report of Indira Gandhi Krishi Vishwavidyalaya, Raipur [20], Pleurotus spp. are produced considerably higher in yield in December.

Based on the result of current study, it could be concluded that the environmental conditions of Bangladesh during winter months (December to February) are more suitable while August to October are unfavorable for the cultivation of oyster mushroom. We suggest cultivation of Pleurotus spp. in the temperature zone $14-27{ }^{0} \mathrm{C}$ with relative humidity $70-80 \%$. If country's environmental condition is not suitable to provide this temperature and relative humidity, mushroom should be cultivated in controlled condition.

\section{Acknowledgements}

This study was supported by the Strengthening Mushroom Development Project of the Ministry of Agriculture, Peoples Republic of Bangladesh.

\section{References}

1. M. A. Khan, S. M. R. Amin, M. N. Uddin, M. Tania, and N. Alam, Bangladesh J. Mushroom 2, 9 (2008).

2. A. F. Van Peer, W. H. Muller, T. Boekhout, L. G. Lugones, and H. A. Wosten, PLoS One 4, e5977 (2009). doi:10.1371/journal.pone.0005977

3. P. Stamets, J. Wild Mushroom 11, 9 (1993).

4. E. L. Schmidt, J. Mycologia 75, 870 (1983).

5. AMGA. The Australian Mushroom Growers Association (AMGA), Locked Bag 3, 2 Forbes St., Windsor, NSW, 2756, Australia (2004)

6. N. C. Sarker, M. M. Hossain, N. Sultana, I. H. Mian, A. J. M. S. Karim, and S. M. R. Amin, Bangladesh J. Mushroom 2, 27 (2008).

7. Z. Bano and S. Rajarathnam, Mushroom J. 115, 243 (1982). 
8. Y. N. Puri and N. Yadav, Mushroom J. 102, 209 (1981).

9. C. O. Rangad and C. L. Jandaik, Indian J. Mushroom 3, 9 (1977).

10. S. S. Block, G. Tsao, and L. H. Hom, J. Agric. Food Chem. 6, 923 (1958). doi:10.1021/jf60094a009

11. H. C. Srivastava and Z. Bano, Appl. Microbiol. 19, 166 (1970). PMid:16349874 PMCid:376631

12. W. S. Kong, Oyster mushroom cultivation, In: Mushroom Growers' Handbook 1 (Mushworld, Korea, 2004) pp. 54-57.

13. S. M. R. Amin, N. C. Sarker, M. Moonmoon, J. Khandaker, and M. Rahman, Officer's Training Manual. (National Mushroom Development and Extension Centre, Savar, Dhaka, Bangladesh 2007) pp. 7-17.

14. W. S. Kong, Oyster mushroom cultivation, In: Mushroom Growers’ Handbook 1 (Mushworld, Korea, 2004) pp. 54-57.

15. G. Viziteu, Substrate-cereal straw and Corn Cobs, In: Mushroom Growers Handbook 1, R. Gush (ed.) (P. and F. Publisher, USA, 2000) pp. 86-90.

16. T. K. Das, R. Sharma, and B. Sing, Utilization of weeds and other waste products for spawn and fruiting body production of Oyster mushroom. In: Sharma, R. (Ed.), Proceedings of the $8^{\text {th }}$ International Symposium. US Department of Agriculture Tech., USA, Bull 84 (3-5 August 1987).

17. T. K. Das, R. Sharma, and B. Singh, Some Principles in Mushroom Growing and Spawn Mocking. US Department of Agriculture Tech., USA, Bull 85, 1 (1991).

18. D. P. Tripathi, Mushroom Cultivation (Oxford and IBH Publishing Co. Pvt. Ltd. New Delhi, 2005) pp. 17 and 210.

19. R. C. Upadhyay, S. K. Singh, and R. D. Rai, Current Vistas in Mushroom Biology and Production (Mushroom Society of India, 2003) pp. 164 and 246.

20. H. Sher, M. A. Yemeni, A. H. A. Bahkali, and H. Sher, Saudi J. of Biol. Sci. 17, 321 (2010).

21. Annual Progress Report, Mushroom Research Laboratory, Department of Plant Pathology. (Indira Gandhi Krishi Vishwavidyalaya, Raipur 492012, M.P., India, 1999-2010). 